\title{
A Diagnosis Approach for Typical Faults of Lithium-ion Battery Based on Extended Kalman Filter
}

\author{
Chao $\mathrm{Wu}^{1,2, *}$, Chunbo Zhu ${ }^{1}$, Yunwang $\mathrm{Ge}^{2}$, Yongping Zhao ${ }^{1}$ \\ ${ }^{1}$ School of Electrical Engineering and Automation, Harbin Institute of Technology, Harbin 150001, \\ People's Republic of China; \\ ${ }^{2}$ Department of Electrical Engineering, Luoyang Institute of Science and Technology. Luoyang \\ 471023, People's Republic of China; \\ E-mail: shiningi@163.com
}

doi: $10.20964 / 2016.06 .66$

Received: 21 December 2015 / Accepted: 7 April 2016 / Published: 4 May 2016

A fault diagnosis approach based on extended Kalman filter and incremental capacity analysis is proposed with fully understanding the internal failure mechanism of lithium-ion battery, which is extremely suitable for dynamic conditions. In order to detect and distinguish the fault modes and bridge fault symptoms with internal mechanisms, a serial of abusive experiments for over-discharge and low-temperature operation, which may commonly occur during battery applications, are arranged. Fault symptoms in form of electrical parameter variation are extracted as diagnosis basis. Furthermore, incremental capacity analysis is applied for isolation of the two similar faults. The diagnosis approach provides detailed description of symptoms and clear meaning of internal mechanisms. Postdisassembly analysis validates its reliability and effectiveness.

Keywords: Fault diagnosis, Lithium-ion battery, Extended Kalman filter, Incremental capacity analysis, Abusive tests.

\section{FULL TEXT}

(C) 2016 The Authors. Published by ESG (www.electrochemsci.org). This article is an open access article distributed under the terms and conditions of the Creative Commons Attribution license (http://creativecommons.org/licenses/by/4.0/). 